\title{
ASPECTOS FONÉTICO-FONOLÓGICOS DO ANGOLAR MODERNO ${ }^{1}$
}

\author{
Manuele BANDEIRA* \\ Ana Lívia AGOSTINHO** \\ Shirley FREITAS ${ }^{* * *}$
}

- RESUMO: Este trabalho tem como objeto o angolar, língua autóctone de São Tomé e Príncipe, e pretende: (i) investigar seus aspectos fonético-fonológicos; e (ii) comparar os resultados da pesquisa com Maurer (1995) e Lorenzino (1998), as primeiras descrições. Como corpus, foram utilizados 3000 itens coletados em duas viagens de campo (em 2014 e 2018) para a comunidade de São João dos Angolares, em São Tomé. Quanto ao quadro consonantal, defendese que o angolar possui 16 fonemas: /p, b, t, d, k, g, f, v, $\theta$, ð, l, m, n, n, j, w/. Este estudo

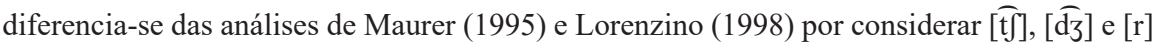
como alofones; por outro lado, os três estudos concordam quanto ao estatuto fonológico das fricativas interdentais. Com relação ao quadro vocálico, o angolar apresenta 14 vogais orais: /i, e, $\varepsilon$, a, o, o, u, ii, ee, $\varepsilon \varepsilon$, aa, $ว$, oo, uu/, sendo possíveis foneticamente realizações nasais. Por fim, quanto à estrutura silábica, foi encontrado um número maior de moldes silábicos, incluindo uma possível realização de onset complexo. Com esse estudo, foi possível conhecer mais acerca da fonologia do angolar, lançando novas luzes sobre uma língua ainda pouco estudada e contribuindo para a área de contato.

- PALAVRAS-CHAVE: angolar moderno; quadro vocálico; quadro consonantal; estrutura silábica.

\section{Introdução}

Este estudo busca investigar aspectos fonético-fonológicos do angolar, uma das três línguas autóctones da República de São Tomé e Príncipe (cf. Fig. 1), ao lado do

\footnotetext{
Universidade da Integração Internacional da Lusofonia Afro-Brasileira (UNILAB). São Francisco do Conde - BA Brasil. manuelebandeira@unilab.edu.br. ORCID: 0000-0002-3163-0377.

** Universidade Federal de Santa Catarina (UFSC). Florianópolis - SC - Brasil. a.agostinho@ufsc.br. ORCID: 00000002-2395-4961.

**** Universidade da Integração Internacional da Lusofonia Afro-Brasileira (UNILAB). São Francisco do Conde - BA Brasil.shirleyfreitas@gmail.com. ORCID: 0000-0001-6124-8067.

1 Agradecemos aos avaliadores pelas sugestões, críticas e comentários que contribuíram enormemente para a melhora do trabalho. Contudo, cabe destacar que quaisquer equívocos ou inadequações que aparecerem no decorrer deste estudo são de nossa inteira responsabilidade.
} 
santome e do lung'Ie. No que tange à localização geográfica da sua comunidade de falantes, o angolar é empregado na ilha de São Tomé. Da população absoluta do referido país (173.015), 11.377 falam o angolar como primeira ou segunda línguas (INE, 2013). Seus falantes vivem nas zonas do litoral de São Tomé, no distrito de Caué, entre Ribeira Afonso até Porto Alegre e, no litoral noroeste, a partir de Neves até Bindá, no distrito de Lembá, e ademais, próximos à cidade de São Tomé, existem pequenos grupos de falantes em São João da Vargem, Pantufo e Praia Melão (CEITA, 1991).

No tocante à gênese do grupo étnico angolar, existem três hipóteses explicativas e simultaneamente excludentes (SEIBERT, 2004). A primeira hipótese, de origem popular e difundida dentre a população local, formulada no século XIX, defende que os angolares são descendentes dos sobreviventes de um naufrágio de um navio de escravizados, em meados do século XVI, oriundo de Angola. A segunda hipótese alega que os angolares seriam habitantes autóctones de São Tomé e, por essa razão, já estariam presentes na ilha no momento em que os portugueses ali aportaram. Por fim, a terceira, conhecida como hipótese dos quilombolas, advoga que os ascendentes dos angolares eram antigos cativos que fugiram para áreas até então inabitadas, construindo uma nova comunidade, posteriormente ampliada com elementos dos recém-fugidos das roças e das cidades, por volta dos séculos XVI e XVII. Baseado em pesquisas de comparações genéticas entre as três línguas, Ferraz (1974) demonstra que o angolar está relacionado linguisticamente ao santome e ao lung'Ie, descartando as hipóteses de naufrágio e de que os angolares já habitavam São Tomé antes de os portugueses chegarem. $\mathrm{O}$ autor então formula a tese de que os escravos fugidos foram expostos às fases formativas do protocrioulo. Nesse sentido, o contato linguístico no processo do povoamento da ilha São Tomé resultou numa língua diversa daquela do colonizador, o protocrioulo do Golfo da Guiné (PGG) (GÜNTHER, 1973; FERRAZ, 1974, 1979; BANDEIRA, 2017) do qual posteriormente o angolar se ramifica.

Figura 1 - Mapa de São Tomé e Príncipe

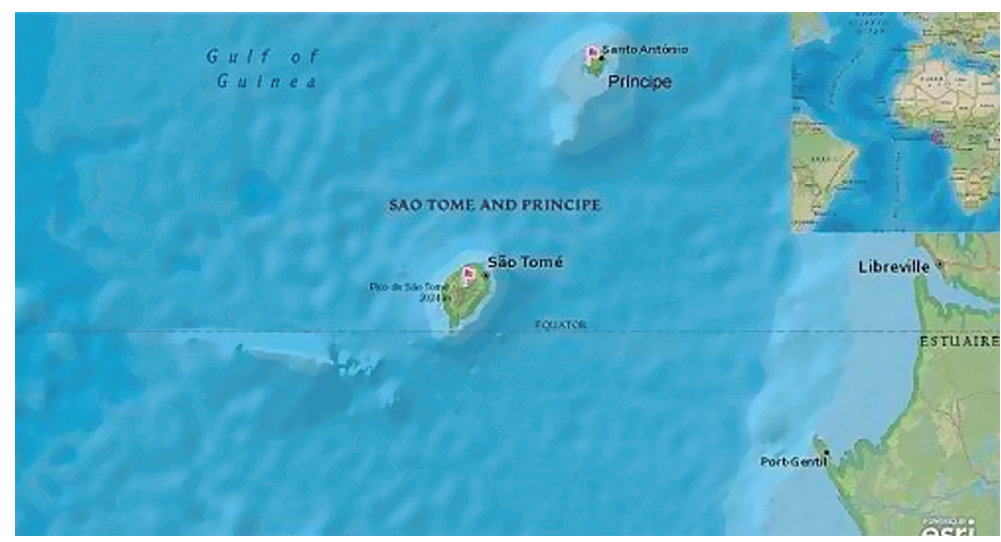

Fonte: Mapmaker (2016). 
Ainda que seja empregado por uma parcela de $6 \%$ da população total do país, a língua não tem sido objeto de estudos descritivos sistemáticos, sendo que o estudo pioneiro foi publicado há mais de duas décadas, intitulado L'angolar. Un créole afroportugais parle à São Tomé. Notes de grammaire, textes, vocabulaire (MAURER, 1995). Três anos depois, um outro estudo foi realizado: The Angolar creole Portuguese of São Tomé: its grammar and sociolinguistic history (LORENZINO, 1998). Em vista disso, em 2014 e em 2018, foram realizadas duas pesquisas de campo na comunidade de São João dos Angolares, pequena vila do distrito de Caué, a fim de coletar dados recentes da língua mencionada. Desse modo, a presente análise possui dois objetivos principais: (i) investigar alguns aspectos fonéticos e fonológicos do angolar moderno, (ii) discutir os pontos convergentes e dissonantes na comparação das amostras coletadas com a descrição apresentada em Maurer (1995) e Lorenzino (1998). Para tanto, o estudo será deslindado da seguinte maneira: inicialmente, abordaremos os materiais e métodos empregados pela análise. Posteriormente, serão apresentadas considerações sobre o angolar feitas por Maurer (1995) e Lorenzino (1998). Em seguida, será a vez de discutir os dados encontrados, comparando-os, ao mesmo tempo, com os aspectos apontados pelos autores supracitados. Para isso, será apresentada a análise no que diz respeito ao quadro consonantal do angolar; a seguir, será a vez de fazer o mesmo quanto ao seu quadro vocálico e, por fim, faremos observações a respeito da estrutura silábica da língua. Reconhecemos que apresentar discussões relacionadas aos sistemas consonantal e vocálico e à sílaba no angolar em um único artigo é uma decisão audaciosa, tendo em vista seu amplo escopo, contudo optamos por tratar destes temas uma vez que, conforme mencionado, a fonologia dessa língua não tem sido foco de muitas pesquisas e os resultados aqui apresentados podem instigar a realização de novos estudos. Por fim, traremos as considerações finais do estudo.

\section{Materiais e métodos}

Para fins de análise, a pesquisa considerou, como ponto de partida, a lista de cerca de 1600 palavras retiradas do trabalho de Maurer (1995). L'angolar. Un créole afroportugais parle à São Tomé. Notes de grammaire, textes, vocabulaire é um dos primeiros e um dos poucos estudos descritivos sobre a língua com análises morfossintáticas em quase sua totalidade (com trinta páginas dedicadas à fonética e à fonologia). Embora a lista de 1600 itens de Maurer (1995) reúna o léxico básico do angolar e, em alguns casos, informação tonal, os dados apresentam uma notação gráfica sem transcrição fonética ou notação fonológica, sobretudo, sem qualquer referência à posição do acento primário. Adicionalmente, materiais de áudio do angolar não se encontravam, até o momento, disponíveis para a consulta.

Para a realização do estudo, por conseguinte, empreenderam-se, no início do ano de 2014 e final de 2018, duas pesquisas de campo na comunidade de São João dos Angolares, em São Tomé. As duas viagens se estenderam por até dois meses, durante as 
quais foi possível fazer gravações com falantes. Além de entrevistas, foram gravadas histórias da comunidade, assim como foram realizados testes com pares mínimos, julgamentos de gramaticalidade e testes de reação subjetiva a fim de confirmar se uma dada realização era possível ou não para que fossem observados aspectos no tocante à fonologia da língua ${ }^{2}$. Durante a pesquisa de campo, foi possível gravar com falantes bilíngues (português e angolar) e também com falantes monolíngues, em geral, idosos, mas também crianças ${ }^{3}$. A gravação com esses falantes foi importante, uma vez que foi possível perscrutar o angolar em seu estado de vernáculo e na sua interface geracional.

Com os dados coletados, iniciou-se o processo de transcrição do material de áudio. Da coleta, foi elaborado um pequeno dicionário com cerca de 3000 verbetes (ARAUJO; BANDEIRA, em preparação) com transcrições fonéticas, que serviu como fonte para essa pesquisa. Posteriormente, com as primeiras etapas concluídas, deu-se início ao processo de análise dos dados, em que se observaram alguns pontos conflitantes na comparação das amostras com a descrição de Maurer (1995) e de Lorenzino (1998). Em vista disso, abordaremos tais aspectos convergentes e discordantes, destacando as semelhanças e esquadrinhando possíveis razões para as diferenças.

\section{Estudos prévios a respeito do angolar}

No tocante às suas especificidades, o angolar apresenta uma parcela de léxico bantu que não se encontra nas demais línguas autóctones de São Tomé e Príncipe, a exemplo do sistema de numerais cardinais que somente se assemelha ao lung' $\mathrm{Ie}^{4}$ e ao santome até o número três, posto que, a partir do número quatro, o angolar apresenta itens semelhantes ao kimbundu (CHATELAIN, 1888-1889; MAURER, 1995; LORENZINO, 1998; BANDEIRA, 2017), como se observa no Quadro 1.

\footnotetext{
Quanto às gravações realizadas, nos registros já apareciam algumas alofonias, como entre $[\mathrm{d}] \mathrm{e}[\mathrm{r}],[\mathrm{s}] \mathrm{e}[\theta],[\mathrm{z}] \mathrm{e}[ð]$ (conforme se discutirá na seção de análise dos dados). Além disso, nos casos em que havia dúvidas acerca da ocorrência do segmento, foram feitos pedidos de julgamentos também para confirmar, o que se mostrou relevante, por exemplo, na análise das interdentais.

3 Foram encontradas diferenças entre os informantes bilíngues e monolíngues no que tange ao julgamento de alguns segmentos. Os bilíngues, por exemplo, flutuam mais quanto às fricativas interdentais, que são categóricas entre os monolíngues.

4 Não há consenso na literatura que trata da fonologia do lung'Ie (GÜNTHER, 1973; TRAILL; FERRAZ, 1981; MAURER, 2009; AGOSTINHO, 2015; AGOSTINHO; HYMAN, 2021) acerca da classificação de seu sistema suprassegmental: Günther (1973) considera que se trata de uma língua tonal com três tons, Traill e Ferraz (1981) a classificam como uma língua pitch-accent livre, Maurer (2009) a analisa como uma língua tonal com dois tons, Agostinho (2015) propõe um sistema misto de tom e acento e Agostinho e Hyman (2021) apresentam um sistema tonal privativo. Assumimos aqui a análise de Agostinho e Hyman (2021). Em relação ao angolar, Maurer (1995) e Lorenzino (1998) propõem que o angolar apresenta tom lexical, mas não apresentam uma análise fonológica aprofundada. Neste trabalho, não abordaremos a descrição do sistema suprassegmental do angolar, que será foco de pesquisas futuras, e utilizaremos a marcação acento para indicar a proeminência lexical.
} 
Quadro 1 - Os números cardinais nas línguas de

São Tomé e Príncipe e em kimbundu

\begin{tabular}{|c|c|c|c|c|}
\hline Numeral & Angolar & Santome & Lung'Ie & Kimbundu \\
\hline $\mathbf{U m}$ & {$[\text { 'ũe }]^{5}$} & ['ũe] & [û́a] & $<\operatorname{moxi}>$ \\
\hline Dois & ['dosv] & ['dosv] & [dósu] & $<$ lari $>$ ou $<$ ladi $>$ \\
\hline Três & ['te: $\left.\int \mathrm{I}\right]$ & {$\left[\right.$ 'tle $\left.\int_{\mathrm{I}}\right]$} & [tě: $: j i]$ & $<$ tatu $>$ \\
\hline Quatro & ['kwane] & ['kwatlu] & [kwátu] & $<$ uana $>$ \\
\hline Cinco & [ta'no] & ['Jîkv] & [ fíku] & $<\operatorname{tanu}>$ \\
\hline Seis & [sa'mãñ̃] & {$\left[' \operatorname{se} \int \mathrm{I}\right]$} & [séj] & $<$ samanu $>$ \\
\hline Sete & [sãba'di] & {$[$ 'sct $\varepsilon]$} & [sćt $\left.\int \mathrm{i}\right]$ & $<$ sambuadi $>$ \\
\hline Oito & {$\left[\mathrm{na}{ }^{\prime} \mathrm{k} \varepsilon\right]$} & ['woto] & [wétu] & $<$ nake $>$ \\
\hline Nove & [u'vwa] & ['n๑ve] & [nóve] & $<$ ivua $>$ ou $<$ vua $>$ \\
\hline Dez & ['kwĩ] & {$[\mathrm{d} d \varepsilon \mathrm{f}]$} & [défi] & $<$ kuinii $>$ ou $<$ kuinhi $>$ \\
\hline
\end{tabular}

Fonte: Dados modificados de Bandeira (2017).

A partir da análise de todas as palavras de étimo africano pertencentes ao angolar, observa-se que $92 \%$ são palavras derivadas de línguas do grupo bantu, $6 \%$ de étimo edoíde e $2 \%$ yorubá e outras línguas (LADHAMS, 2007). O grande influxo bantu no angolar se deve ao deslocamento da região de sequestro da população africana escravizada, na fase de plantação em São Tomé, a partir de 1520, que muda do Benin, onde se falavam línguas do grupo Edo (por isso 6\%), para zonas bantu, primeiro o Congo e pouco depois Angola, onde eram faladas, entre outras línguas bantu, o kikongo e o kimbundu (HAGEMEIJER, 2009). Assim, o angolar, fruto da especiação do PGG dentro de uma comunidade quilombola, desenvolveu-se com menos pressões do elemento luso, devido ao relativo isolamento, e implementado com o aporte bantu devido à participação de ex-cativos foragidos provenientes das zonas bantu. Os itens de étimo yorubá podem ser entendidos a partir do fato de que os cativos eram negociados originalmente na região do Itisikiri, cuja língua é próxima do yorubá. Além disso, em razão da importância do yorubá como língua regional, pode ter sido uma segunda língua para alguns falantes de Edo conforme aponta Ladhams (2007).

\footnotetext{
Algumas considerações sobre a notação aqui empregada: Os itens do angolar e das demais línguas autóctones de São Tomé e Príncipe (santome e lung'Ie) são apresentados de três formas: (i) conforme sua realização fonética; (ii) de acordo com sua representação fonológica; e (iii) em consonância com a grafia oficial da língua (BANDEIRA, 2017). A primeira representação é indicada pelos colchetes [ ] como em ['ba: $\theta \mho]$ 'braço' em angolar. O acento primário foi indicado - somente nas transcrições fonéticas - pelo símbolo (') antecedendo a sílaba tônica como em ['budv] 'pedra' em angolar. A glosa é indicada após a(s) palavra(s) referida(s), entre aspas simples (exemplo: 'pedra'). Os símbolos utilizados na transcrição estão de acordo com o Alfabeto Fonético Internacional (AFI) da International Phonetic Association, IPA, revisado em 2015. A representação fonológica, por sua vez, é identificada pelas barras inclinadas // como em /lala/ 'ralar' em santome. Já a representação por meio da grafia oficial é sinalizada em negrito, como a palavra dhumbo 'bigode' em angolar. O emprego de tal grafia obedece às regras do Alfabeto Unificado para as Línguas Nativas de São Tomé e Príncipe (ALUSTP) a fim de se representar alfabeticamente o santome, o lung'Ie e o angolar. Embora as línguas sejam mutuamente ininteligíveis, compartilham um número substancial de propriedades lexicais e gramaticais, o que justifica uma grafia unificada (ARAUJO; AGOSTINHO, 2010).
} 
Ainda que o angolar apresente em seu vocabulário uma presença robusta de palavras de proveniência africana (especialmente bantu), seu léxico básico é predominantemente de étimo português. A partir de uma contagem da lista do léxico nuclear das línguas autóctones de São Tomé e Príncipe (angolar, santome, lung'Ie), Hagemeijer (2009) demonstra que o angolar apresenta uma porcentagem aproximada de $82 \%$ de léxico de origem portuguesa, ao lado do santome e do lung'Ie que apresentam $93 \%$. A maior participação de itens de étimo português no léxico comum das referidas línguas foi corroborada por Bandeira (2017) a exemplo dos itens no Quadro 2 que se referem à anatomia humana, sendo palavras do vocabulário básico, cuja presença pode ser remontada ao período de formação das três línguas.

Quadro 2 - Itens de étimo português em angolar, santome e lung'Ie

\begin{tabular}{|c|c|c|c|}
\hline Português & Angolar & Santome & Lung'Ie \\
\hline Braço & ['ba: $\theta v]$ & ['blasv] & [ubă:su] \\
\hline Boca & ['boke] & ['boke] & [ubúka] \\
\hline Dente & {$\left[' \operatorname{det} \int \mathrm{I}\right]$} & ['dẽt $\left.\int \mathrm{I}\right]$ & [idî́tji] \\
\hline Osso & ['o 00$]$ & ['oso] & [ósu] \\
\hline Coração & [ko' $\theta 0]$ & [klo'sõ] & [kosố $]$ \\
\hline$P e ́$ & [o'p $\mathrm{p}]$ & {$\left[\rho^{\prime} \mathrm{p} \varepsilon\right]$} & [эpéc] \\
\hline
\end{tabular}

Fonte: Dados modificados de Bandeira (2017).

No tocante ao estabelecimento do quadro fonológico da língua, há duas propostas relativamente recentes. A primeira feita por Maurer (1995) e a segunda por Gerardo Lorenzino (1998) em sua tese de doutoramento. De acordo com Maurer (1995) e Lorenzino (1998), o angolar possui 12 fonemas vocálicos, sendo sete vogais orais, cinco vogais nasais. O Quadro 3 apresenta as vogais do angolar de acordo com os dois autores:

Quadro 3 - Vogais do angolar segundo Maurer (1995) e Lorenzino (1998)

\begin{tabular}{ccc}
\hline & Maurer (1995) & Lorenzino (1998) \\
Vogais orais & $/$ a $\varepsilon$ e i o o u/ & $/$ a $\varepsilon$ e i o o u/ \\
Vogais nasais & $/$ ĩ ẽ ã õ ũ/ & /̃ ẽ ã õ ũ// \\
\hline
\end{tabular}

Fonte: Elaboração própria.

De acordo com Maurer (1995), o sistema fonológico do angolar é constituído de um total de vinte e cinco (25) fonemas. Contudo, o sistema não é estável em vários pontos, a saber:

6 As transcrições com outros alfabetos fonéticos foram adaptadas para o International Phonetic Alphabet (IPA). 

a) as vogais nasais;
b) os sons nasais;
c) as consoantes chamadas de pré-nasalizadas e;
d) a oposição entre as consoantes $/ \mathrm{r} / \mathrm{e} / \mathrm{l} /$.

O autor atribui tal instabilidade, em parte, ao contato com o santome e, em parte, ao contato em um certo nível com o português. Além dos vinte e cinco fonemas, o angolar apresentaria os fones [S] e [3] em palavras emprestadas (MAURER, 1995). Nas palavras de Maurer (1995, p.38), [d] seria uma variante "mais ou menos livre" de [r]. As consoantes propostas pelos dois autores podem ser observadas no Quadro 4:

Quadro 4 - Consoantes do angolar segundo Maurer (1995) e Lorenzino (1998)

\begin{tabular}{|c|c|c|}
\hline & Maurer (1995) & Lorenzino (1998) \\
\hline Oclusivas & $/ \mathrm{p} 6 \mathrm{t} \mathrm{k} \mathrm{g/}$ & $/ \mathrm{p} 6 \mathrm{td} \mathrm{kg} /$ \\
\hline Fricativas & /f v $\theta$ ð/ & $/ \mathrm{fvsz} \theta \partial /$ \\
\hline Africadas & $/ \mathrm{t} \int \mathrm{d}_{3} /$ & $/ \mathrm{t} \int \mathrm{d}_{3} /$ \\
\hline Líquidas & $/ 1 \mathrm{r} /$ & $/ 1 \mathrm{r} /$ \\
\hline Nasais & $/ \mathrm{m} \mathrm{n} /$ & $/ \mathrm{mnj} \mathrm{y} /$ \\
\hline Pré-nasalizadas $^{7}$ & $\mathrm{mp} \mathrm{mb}$ nd nd3 $\mathrm{yk}$ yg nf & mb mp yk yg nf nt nz \\
\hline Alofones & {$\left[\mathrm{d} \int 3\right]$} & {$\left[\int 3\right]$} \\
\hline Glides & $/ \mathrm{j} w \tilde{\mathrm{j}} /$ & $/ \mathrm{j} \mathrm{w} /$ \\
\hline
\end{tabular}

Fonte: Elaboração própria.

Enquanto Maurer (1995) propõe um quadro consonantal com vinte e cinco fonemas, Lorenzino (1998), por seu turno, apresenta um quadro consonântico um pouco menor, constituído de vinte e dois (22) fonemas. As principais diferenças com relação à análise de Maurer são: /d/ é um fonema (tratado como alofone por Maurer); por fim, as consoantes $/ \mathrm{y} /$ e / $\mathrm{n} /$ são distintivas na análise empreendida pelo autor (LORENZINO, 1998). Ademais, Maurer (1995) aponta a existência de alofones para os seguintes fonemas:

- /n/ - realizado como [m] diante de [m], [b] e [p]; [n] diante de [g] e [k], e [n] em todos os outros casos.

- $/ \theta /$ - realizado como [s] diante de [i].

- /ð/ - realizado como [z] diante de [i].

Semelhantemente ao observado por Maurer (1995), Lorenzino (1998) acredita que o angolar apresenta três nasais silábicas em distribuição complementar: [m] diante de

A partir da descrição dos autores, não fica claro se tais segmentos seriam fones ou fonemas da língua. 
/m/ e /p/ (mme 'comer'), [y] antes de /k/ e /g/ (nkila 'rabo') e [n] em todos os outros contextos (nfara 'travesseiro').

Passando para as estruturas silábicas, no Quadro 5 aparecem os padrões silábicos apontados por Maurer (1995) e Lorenzino (1998) como possíveis no angolar:

Quadro 5 - Estruturas silábicas do angolar segundo

Maurer (1995) e Lorenzino (1998)

\begin{tabular}{|c|c|c|}
\hline & Maurer (1995) & Lorenzino (1998) \\
\hline $\mathbf{V}$ & a $\mathrm{PRO}^{8}$ & a PRO \\
\hline VV & ôu 'costurar' & -- \\
\hline $\mathrm{CV}$ & pê 'pôr' & ta $\mathrm{TMA}^{9}$ \\
\hline CVV & fiira 'ferida' & beqga 'barriga' \\
\hline CGV & --- & kwa 'coisa' \\
\hline $\mathrm{VC}$ & 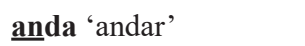 & --- \\
\hline
\end{tabular}

Fonte: Elaboração própria.

Após uma breve observação de estudos que ensejaram o estabelecimento de um quadro fonológico para o angolar, na próxima seção, defenderemos um quadro distinto daquele apresentado até aqui.

\section{Análise dos dados}

A descrição do inventário fonológico do angolar, a seguir, foi baseada na análise empreendida por meio de dados coletados e transcritos em trabalho de campo, ao mesmo tempo em que uma revisão de descrições apresentadas por Maurer (1995) e Lorenzino (1998) serviu como contraponto para o estudo.

Nas próximas subseções, serão discutidas as questões sobre as quais a pesquisa se debruçou, tais como (i) o estatuto alofônico para [ [t]] e [ $\widehat{\mathrm{d}} 3]$; (ii) o estatuto fonêmico para /n/; (iii) o estabelecimento de uma consoante nasal sem ponto de articulação definido representada por /N/; (iv) a existência de vogais nasais ou nasalizadas; (v) a definição da estrutura e das restrições silábicas.

Desse modo, começaremos pelo quadro fonológico das consoantes.

\section{Quadro consonantal do angolar}

No tocante ao quadro de consoantes do angolar, a análise defende que a língua possui dezesseis fonemas consonantais: /p, b, t, d, k, g, f, v, $\theta$, ə, l, m, n, j, j, w/. Nas

\footnotetext{
8 Pronome indefinido.

9 Partícula de tempo, modo e aspecto.
} 
próximas subseções, serão apresentadas brevemente as realizações e oposições de cada consoante que fundamentaram o estabelecimento do quadro fonêmico.

\section{Oclusivas}

$\mathrm{O}$ angolar possui seis consoantes oclusivas em seu quadro fonêmico: duas consoantes oclusivas bilabiais $/ \mathrm{p} / \mathrm{e} / \mathrm{b} /$, duas consoantes oclusivas alveolares $/ \mathrm{t} / \mathrm{e}$ /d/ e duas consoantes oclusivas velares /k/ e /g/. Exemplos de pares mínimos dessas consoantes são apresentados no Quadro 6:

Quadro 6 - Pares mínimos - consoantes oclusivas

\begin{tabular}{|c|c|c|c|c|c|}
\hline \multicolumn{2}{|c|}{ Bilabiais } & \multicolumn{2}{|c|}{ Alveolares } & \multicolumn{2}{|c|}{ Velares } \\
\hline$/ \mathbf{p} /$ & $/ \mathbf{b} /$ & $/ \mathbf{t} /$ & $/ \mathbf{d} /$ & $/ \mathbf{k} /$ & $/ g /$ \\
\hline $\begin{array}{l}\text { /p/ [pa'ga] } \\
\text { 'pagar' }\end{array}$ & $\begin{array}{l}/ \mathbf{b} / \text { ['ba:tv] } \\
\text { 'barato' }\end{array}$ & $\begin{array}{l}/ \mathbf{t} /[\text { 'tazi }] \\
\text { 'tarde' }\end{array}$ & $\begin{array}{l}/ \mathbf{d} /[\mathrm{kõ} \text { 'de }] \\
\text { 'esconder' }\end{array}$ & $\begin{array}{l}\text { /k/ [ [j'ka] } \\
\text { 'empurrar' }\end{array}$ & $\begin{array}{l}/ \mathbf{g} /\left[1 \mathrm{ov'}^{\prime} \text { ga }\right] \\
\text { 'prato, tigela' }\end{array}$ \\
\hline $\begin{array}{l}\text { /b/ [ba'ga] } \\
\text { 'quebrar' }\end{array}$ & $\begin{array}{l}/ \mathbf{p} /[\text { pa:to] } \\
\text { 'prato' }\end{array}$ & $\begin{array}{l}/ \mathbf{d} /[\text { 'dazi }] \\
\text { 'idade' }\end{array}$ & $\begin{array}{l}\text { /t/ [ [kõ'te] } \\
\text { 'odiar' }\end{array}$ & $\begin{array}{l}/ g /\left[\int i ' g a\right] \\
\text { 'chegar' }\end{array}$ & $\begin{array}{l}\text { /k/ [lõ'ka] } \\
\text { 'roncar' }\end{array}$ \\
\hline $\begin{array}{l}\text { /p/ ['peme] } \\
\text { 'palmeira' }\end{array}$ & $\begin{array}{l}\text { /b/ ['bale }] \\
\text { 'bala' }\end{array}$ & $\begin{array}{l}\text { /t/ [ko'ta] } \\
\text { 'cortar' }\end{array}$ & $\begin{array}{l}/ \mathbf{d} /\left[\mathrm{da}{ }^{\prime} \mathrm{da}\right] \\
\text { 'dada, peixe }\end{array}$ & $\begin{array}{l}\text { /k/ ['kate] } \\
\text { 'carta' }\end{array}$ & $\begin{array}{l}\text { /g/ [be'ge] } \\
\text { 'esmagar' }\end{array}$ \\
\hline $\begin{array}{l}/ \mathbf{m} /[\text { 'meme }] \\
\text { 'dois' }\end{array}$ & $\begin{array}{l}/ \mathbf{v} /[\text { 'vale }] \\
\text { 'vara' }\end{array}$ & $\begin{array}{l}/ \theta /[\mathrm{ko} \cdot \theta \mathrm{a}] \\
\text { 'coçar' }\end{array}$ & $\begin{array}{l}\text { (sp.)' } \\
\text { /n/ [na'na] } \\
\text { 'estragar' }\end{array}$ & $\begin{array}{l}/ \mathbf{p} /[\text { 'pate }] \\
\text { 'pata' }\end{array}$ & $\begin{array}{l}/ \mathbf{b} /[\mathrm{be} \text { 'be }] \\
\text { 'beber' }\end{array}$ \\
\hline
\end{tabular}

Fonte: Dados retirados de Bandeira (2017).

\section{Nasais}

$\mathrm{O}$ angolar apresenta em seu quadro fonêmico três consoantes nasais: a consoante nasal labial $(/ \mathrm{m} /)$, a consoante nasal alveolar (/n/) e uma consoante nasal palatal $(/ \mathrm{n} /)$, como se observam nos pares mínimos do Quadro 7:

Quadro 7 - Pares mínimos - consoantes nasais

\begin{tabular}{|c|c|c|}
\hline Labial & Alveolar & Palatal \\
\hline$/ \mathbf{m} /$ & $/ \mathbf{n} /$ & $/ \mathbf{n} /$ \\
\hline /m/ ['peme] 'palmeira' & $/ \mathbf{n} /$ [te' na] 'bastar' & /n/ [ku'na] 'cair, machucar' \\
\hline \multirow[t]{2}{*}{ /n/ ['pene] 'pena' } & $/ \mathbf{t} /[$ te'ta] 'casca' & /m/ [ku'ma] 'comadre' \\
\hline & & /n/ [ku'na] 'plantar' \\
\hline$/ \mathbf{m} /[$ 'male] 'intestinos' & /n/ ['na] 'não' & /n/ [ne'ga] 'pendurar' \\
\hline /b/ ['bale] 'bala' & $/ \mathbf{d} /[$ 'da] 'dar' & /n/ [ne'ga] 'negar' \\
\hline
\end{tabular}

Fonte: Dados retirados de Bandeira (2017). 


\section{Lateral alveolar}

O angolar possui em seu quadro fonêmico apenas uma consoante lateral: a consoante lateral alveolar (/1/), sendo alguns pares mínimos apresentados no Quadro 8:

\begin{tabular}{|c|}
\hline Lateral alveolar \\
\hline$/ \mathbf{l} /$ \\
\hline /l/ [lẽ'ba] 'cobrir' \\
\hline 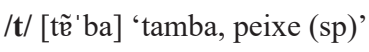 \\
\hline /l/ ['late] 'lata' \\
\hline /d/ ['date] 'quantidade' \\
\hline
\end{tabular}

Fonte: Dados retirados de Bandeira (2017).

\section{Fricativas}

No angolar, há quatro consoantes fricativas: duas consoantes labiais, uma surda /f/ e uma sonora $/ \mathrm{v} /$ e duas consoantes interdentais, uma consoante surda $/ \theta /$ e uma sonora /ð/. Alguns pares mínimos aparecem no Quadro 9:

Quadro 9 - Pares mínimos - consoantes fricativas

\begin{tabular}{|c|c|c|c|}
\hline \multicolumn{2}{|c|}{ Labiais } & \multicolumn{2}{|c|}{ Interdentais } \\
\hline$/ \mathbf{f} /$ & $/ \mathbf{v} /$ & $/ \theta /$ & /ð/ \\
\hline \multirow{5}{*}{$\begin{array}{l}\text { /f/ [fe'ga] 'esfregar' } \\
\text { /v/ [ve'ga] 'levar' } \\
\text { /p/ [pe'ga] 'pegar, } \\
\text { pregar' }\end{array}$} & /v/ [vu'na] 'banco' & $/ \boldsymbol{\theta} /[$ 'ba: $\theta \mathfrak{e}]$ 'braça & /ð/ ['ða] ‘já' \\
\hline & /f/ [fu'na] & (unidade de medida)’ & $/ \boldsymbol{\theta} /[$ [' $\theta \mathrm{a}]$ 'estar' \\
\hline & 'embrulhar' & /t/ ['ba:te] 'barata' & \\
\hline & /v/ ['vale] 'vara' & & /ð/ ['ðake] 'jaca' \\
\hline & /b/ ['bale] 'bala' & & /f/ ['fake] 'faca' \\
\hline
\end{tabular}

Fonte: Dados retirados de Bandeira (2017).

\section{Aproximantes}

No angolar, há duas consoantes aproximantes: uma consoante aproximante labial sonora /w/ e uma consoante palatal sonora /j/, com o Quadro 10 trazendo alguns pares mínimos. 
Quadro 10 - Pares mínimos - consoantes aproximantes

\begin{tabular}{|c|c|}
\hline Labial & Palatal \\
\hline$/ \mathbf{w} /$ & $/ \mathbf{j} /$ \\
\hline /w/ ['we] 'olho' & /j/ [ko'je] 'escolher' \\
\hline /b/ ['be] 'ver' & /ð/ [ko'ðе] 'coser' \\
\hline /w/ ['awe] 'água' & /j/ [ta'ja] 'talhar' \\
\hline /ð/ ['aðe] 'asa' & $/ \mathbf{t} /[$ ta' ta] 'tratar' \\
\hline
\end{tabular}

Fonte: Dados retirados de Bandeira (2017).

Após demonstrar o estatuto fonêmico das dezesseis consoantes do angolar, a seguir discutiremos as semelhanças e divergências entre o presente estudo e a proposta de Maurer (1995) e Lorenzino (1998), reservando as seções posteriores para a discussão das consoantes interdentais e o estatuto fonêmico ou alofônico do rótico [r].

\section{Quadro consonantal do angolar: semelhanças e divergências}

A partir da observação dos dados em geral e no levantamento dos pares mínimos apresentados nas subseções anteriores, estabelecemos que o angolar possui dezesseis fonemas consonantais (ver Quadro 11): /p, b, t, d, k, g, f, v, $\theta$, ə, l, m, n, n, j, w/.

Quadro 11 - Consoantes do angolar

\begin{tabular}{lllll}
\hline & \multicolumn{1}{c}{ Labiais } & Alveolares & Palatais & Velares \\
\hline Oclusivas & $\mathrm{p} \mathrm{b}$ & $\mathrm{t}$ & & $\mathrm{k} \mathrm{g}$ \\
Fricativas & $\mathrm{f} \mathrm{v}$ & $\theta$ ð & & \\
Nasais & $\mathrm{m}$ & $\mathrm{n}$ & $\mathrm{n}$ & \\
Laterais & & 1 & & \\
Aproximantes & $\mathrm{w}$ & & $\mathrm{j}$ & \\
\hline
\end{tabular}

Fonte: Adaptado de Bandeira (2017, p.209).

No entanto, segundo Maurer (1995), a referida língua possui vinte e cinco fonemas:

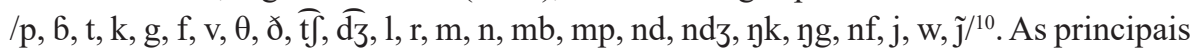
diferenças entre as descrições de Maurer e aquela apresentada por esse estudo estão relacionadas aos seguintes pontos no tocante às consoantes: (i) o estatuto alofônico para

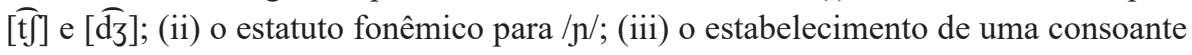
nasal sem ponto de articulação definido representada por /N/; (iv) o estatuto alofônico de [r], que será discutido posteriormente. Quanto à análise de Lorenzino (1998), as

10 Como mencionado, não é claro se Maurer (1995) considera as pré-nasalizadas fonemas. 
principais diferenças se referem ao estatuto alofônico para $[\mathrm{s}]$ e $[\mathrm{z}],[\widetilde{\mathrm{t}}]$ e $[\widehat{\mathrm{d}} \mathrm{z}],[\mathrm{r}]$, aspectos já apontados com relação a Maurer (1995). Outro ponto em que a análise aqui proposta diverge da de Lorenzino (1998) se refere ao estatuto da nasal velar, que não é considerada como fonema, dado que não foram encontrados pares mínimos. Um ponto convergente das três pesquisas diz respeito à presença das consoantes fricativas interdentais no quadro fonológico do angolar, aspecto a ser abordado na seção seguinte, que também discutirá o estatuto de [s] e [z]. Os aspectos divergentes mencionados em (i), (ii) e (iii), por sua vez, serão tratados na presente seção.

A primeira diferença entre as análises se refere à atribuição do caráter fonêmico para as consoantes $[\widehat{\mathrm{t}}]$ e $[\widehat{\mathrm{d}} \mathrm{J}]$, as quais, para esse estudo, não seriam fonemas como defendem Maurer (1995) e Lorenzino (1998), mas alofones, uma vez que sua realização se restringe a contextos em que as consoantes $/ \mathrm{t} / \mathrm{e} / \mathrm{d} /$ são seguidas pela vogal alta coronal /i/ ou pela aproximante /j/ com em (01):
(01) a. [ka't tje] 'talvez'
b. [' fวิt $\mathrm{t} \mathrm{I}]$ 'têmpora'
c. $\left[\mathrm{m} \tilde{\varepsilon}:\right.$ ' $\left.\mathrm{d}_{3} \mathrm{j} \jmath \mathrm{ke}\right]$ 'mandioca'

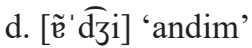

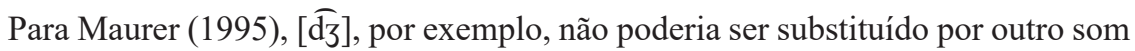

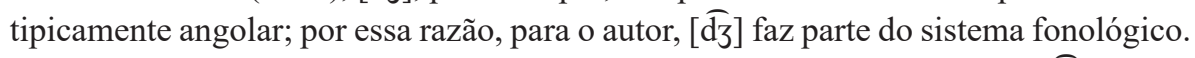
Entretanto, durante a análise dos dados, percebeu-se que a realização de [ $\widehat{\mathrm{d}}$ ] $]$, assim como [ [f] , estava relacionada diretamente aos contextos em que havia a vogal alta coronal /i/ ou uma aproximante /j/ imediatamente depois da oclusiva alveolar sonora

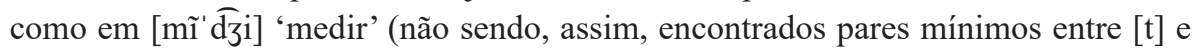
$\left[\widehat{t} \int\right]$ e $[\mathrm{d}]$ e $\left.[\widehat{\mathrm{d}}] \mathrm{f}\right)$. Por conseguinte, as consoantes africadas não podem ser consideradas fonemas na língua.

Ademais, através da recolha de pares mínimos, constatou-se que a consoante nasal palatal / $\mathrm{n} /$ é um fonema no quadro consonantal do angolar, como apontado por Lorenzino (1998). O seu estatuto fonêmico pode ser verificado ao observar as oposições de /n/, $/ \mathrm{m} /$ e $/ \mathrm{n} /$ em (02) e de /n/ e /n/ em (03) (já apresentadas no Quadro 7).

(02) /n/ [ku'na] 'cair, machucar'

$/ \mathrm{m} /$ [ku'ma] 'comadre'

/n/ [ku'na] 'plantar'

(03) / / $/$ [ne'ga] 'pendurar'

$/ \mathrm{n} /[\mathrm{nc}$ ' ga] 'negar' 
Em seus dados, Maurer não descreve a realização da consoante [n] mesmo antes de outra consoante, assim, não há, por exemplo, considerações a respeito de contextos em que há uma consoante com o traço palatal. Só há menção para consoantes com o traço velar, em que o $<\mathrm{n}>$ silábico se comportará como velar ([y]) ou como bilabial ([m]) diante de consoantes labiais. Em todos os demais casos, Maurer afirma que a realização da consoante nasal será [n]. A presente pesquisa, ao analisar os pares mínimos e perceber que a nasal palatal não se restringe a contextos em que há vogal alta coronal /i/ ou aproximante palatal/j/, defende o seu estatuto fonêmico. No entanto, a consoante tem uma distribuição reduzida, assim como em lung'Ie (AGOSTINHO, 2015) e em português, em que as palatais não apresentam alta carga funcional quando comparadas com outros pares fonêmicos (AGOSTINHO; SOARES; MENDES, 2020). Outra análise possível é considerar que /n/ é fonologicamente uma sequência de nasal mais glide /nj/ que pode ser realizada foneticamente como [n], uma vez que não há distinção de /n/ e /nj/ como em russo, por exemplo (BAKER, 2004). Casagrande (1984 apud BAKER, 2004) propõe uma análise similar para o francês, em que [n] é derivado de /ni/.

Dando prosseguimento à discussão, Maurer (1995) estabelece que o angolar apresenta em seu inventário sete consoantes pré-nasalizadas ${ }^{11}[\mathrm{mb}, \mathrm{mp}, \mathrm{nd}, \mathrm{nd}, \mathrm{nk}$, yg, mf]. Lorenzino (1998) aponta essas consoantes como realizações fonéticas. Neste estudo, assumiremos uma consoante nasal sem ponto de articulação definido que pode ser realizada como /m, n, y/ ao assimilar o ponto da consoante seguinte, assim como foi documentado nas suas línguas-irmãs (cf. AGOSTINHO, 2015; BANDEIRA, 2017). A consoante nasal é silábica em início de palavra quando precede as consoantes $/ \mathrm{p} \mathrm{b} \mathrm{t} \mathrm{d} \mathrm{k}$ $\mathrm{g} f \mathrm{v} \theta$ ð/. Assim, a nasal /N/ assimilará o ponto de articulação da consoante seguinte, realizando-se como [n] diante das alveolares /t d/ e interdentais /ð $\theta /$, em (04a), como [m] diante das labiais /p b f v/, em (04b), e como [y] diante das velares /k g/, em (04c).

(04) a. [n] [ndu'lu] 'molde'

b. $[\mathrm{m}][$ m'pune] 'joelho'

c. $\left[\eta \eta_{1}\right]\left[\eta_{i} \mathrm{ko} \mathrm{m \varepsilon}\right]$ 'punho'

Assim como em lung'Ie (AGOSTINHO, 2015), as nasais silábicas em angolar podem variar com [ĩ] em alguns contextos ou com o apagamento total como em (05).

(05) a. [n] [ndu'lu] [ĩdu'lu] [du'lu] 'molde'

b. $[\mathrm{m}][$ mị'pune $] \sim$ [ĩ' pune $] \sim$ ['pune] 'joelho'

c. $[\underline{\eta}]\left[\eta_{1} k \jmath^{\prime} m \varepsilon\right] \sim[i ̃ k o ' m \varepsilon]$ 'punho'

Nesta análise, defendemos que não podem ser consideradas fonemas as sequências consoante nasal consoante oclusiva/fricativa tautossilábicas (referidas na literatura

11 Como já sinalizado, Maurer (1995) não deixa evidente, em sua análise, se considera as pré-nasalizadas fonemas. 
como consoantes pré-nasalizadas), pois, em angolar, as nasais são heterossilábicas, o que impede de serem consideradas como pré-nasalizadas e um só fonema, como nas línguas bantu (NGUNGA, 2004; ANDRADE, 2007). O mesmo posicionamento tem sido tomado para as nasais silábicas do lung'Ie, sua língua-irmã (AGOSTINHO, 2015). Segundo Araujo e Agostinho (2014), jogos de linguagem são normalmente utilizados como argumento quanto à estrutura silábica (cf. DAVIS; HAMMOND, 1995; BOTNE; DAVIS, 2000). Araujo e Agostinho (2014), Agostinho (2015) e Agostinho e Araujo (2021) descrevem um jogo de linguagem em fa d'Ambô e em lung'Ie, línguas-irmãs do angolar, que serve como argumento para a consoante nasal silábica. Assim, no jogo, uma sílaba com onset [p] mais vogal cópia é inserida após a sílaba (com tom alto e/ ou em posição final, para o lung'Ie), portanto o material segmental a ser copiado é o núcleo da sílaba, independentemente do onset ser simples ou complexo. Além disso, a coda aparece somente na sílaba inserida. A seguir podemos observar exemplos do lung'Ie (AGOSTINHO; ARAUJO, 2021):

(06) Lung'Ie
Base
Jogo
Glosa
a. [udćdu] [udepédu] 'dedo'
b. [prímu [pripímu] 'primo'
c. [Jtrínki] [Jtripínki] 'novo'
d. [gófto] [gopófto] 'gosto'

Quando há uma nasal silábica, será inserido [u], conforme os seguintes exemplos (AGOSTINHO; ARAUJO, 2021):

\begin{tabular}{llllll} 
& Fa d'Ambô & \multicolumn{5}{c}{ Lung'Ie } \\
Base & Jogo & Glosa & Base & Jogo & Glosa \\
ṇda & mpundapa & 'andar' & y & mpu & 1 ȘG $^{12}$
\end{tabular}

A partir do exemplo em (07), é possível observar que a nasal silábica é vista como uma sílaba nas duas línguas, conforme argumentado por Araujo e Agostinho (2014) e Agostinho (2015), uma vez que se comporta de maneira diferente em relação a encontros consonantais tautossilábicos, como em [pripímu], em que o resultado não é *[puripímu]. Sendo assim, o jogo de linguagem evidencia o estatuto heterossilábico da nasal.

\section{Consoantes interdentais}

Com relação às fricativas alveolares e interdentais, Maurer (1995) alega uma distribuição complementar entre as fricativas surdas [s] e [ $\theta]$ e as sonoras [z] e [ð].

12 Pronome de primeira pessoa do singular. 
Desse modo, as alveolares, [s] e [z], seriam realizadas diante de /i/, ao passo que as interdentais, $[\theta]$ e $[ð]$, seriam realizadas diante das demais vogais. Por conseguinte, a ocorrência de [s] e [z], diante de vogais que não sejam [i], seria rara, segundo Maurer, sendo apenas encontrada em empréstimos recentes do português e do santome, como zulu ['zulv] 'julho', gôsô ['goso] 'gosto' e sala ['salv] 'sala'. Lorenzino (1998) segue essa mesma descrição de Maurer (1995); assim a despeito de defender a existência de quatro fonemas /s/, /z/, / / / e /ð/, o autor aponta a distribuição complementar entre as fricativas surdas e sonoras.

Ao reunir os dados coletados pela pesquisa, observou-se que, na fala dos informantes com idade superior a 60 anos, as interdentais possuem vitalidade e são de fácil registro. Em contrapartida, na fala dos informantes mais jovens, sobretudo entre 25 a 45 anos, as fricativas interdentais já deram lugar às fricativas [s] e [z] não só diante de /i/, mas diante de todas as demais vogais. Dessa maneira, como as faixas etárias com mais idade são aquelas que utilizam as interdentais [ $\theta]$ e [ð], ao passo que os mais jovens as substituíram completamente pelas alveolares $[\mathrm{s}] \mathrm{e}[\mathrm{z}]$, tal quadro pode indicar uma mudança em progresso (cf. WEINREICH; LABOV; HERZOG, 1968; LABOV, 2008) em relação ao traço [estridente]. Como a mudança ainda não se completou, optamos por utilizar as interdentais para representar os fonemas.

Além disso, muitos itens gravados durante a coleta só apresentaram a realização de [s] e [z]. Quando questionado se o item também poderia ser realizado com as interdentais $[\theta]$ e [ð], o falante identificava os itens como possíveis na língua, no entanto, julgando como pertencentes à fala dos 'mais velhos' ou como 'crioulo fundo' (crioulo antigo).

No que diz respeito à fonologia, o presente estudo propõe que a interdental surda $/ \theta /$ seja considerada um fonema, no angolar, ainda que o mesmo se realize como [s] ou até mesmo como [ $\left.\int\right]$ diante de /i/ ou /j/. A interdental sonora / $/$ também deveria ser considerada um fonema. Portanto, o estatuto fonêmico da interdental surda $/ \theta /$ e da interdental sonora /ð/ pode ser observado nas seguintes oposições entre /ð/, /t/ e /f/ como em (08) e (09) e entre /ð/,/f/ e /v/ em (10) e (11) (alguns já apresentados no Quadro 9):

(08) $/ \theta /[$ 'ba: $\theta e]$ 'braça (unidade de medida)'

/t/ ['ba:te] 'barata'

(09) $/ \theta /[$ ' $\theta a]$ 'estar'

/f/ ['fa] 'falar'

(10) /ð/ ['ðake] 'jaca'

/f/ ['fake] 'faca'

(11) /ð/ [ðе̃'de] 'defecar'

/v/ [vẽ'de] 'vender' 
Ademais, para Maurer (1995), além de sílabas como [ji] e [3i] serem raras, não seria comum encontrar realizações de [J] e do [3] antes de vogais no angolar que não fossem /i/ ou a aproximante/j/. Em itens como ngoxi ['ygofi] em vez de ngosi ['ygosi] 'noite', segundo o autor, podem-se conjecturar duas possibilidades para a realização de [fi]: ou se deve a um caso de variação dialetal ou seria um caso de influência do santome. Independentemente da razão pela qual $/ \theta /$ diante de $/ \mathrm{i} /$ se realiza como [Ji], nas gravações com os falantes de angolar, nota-se que a realização da consoante pós-alveolar surda é comum e não poderia mais ser caracterizada como rara conforme mencionado por Maurer (1995). Quanto ao [3], Maurer (1995) defende que só pode ser encontrado nos itens de empréstimo como ['zulv] 'julho' e ['zuno] 'junho'. Para efeitos de comparação, foi possível observar, na fala dos informantes, itens como em (12) e (13).

(12) a. [ziki't'i] 'rude'

b. [zi'lere] 'geladeira'

c. ['zĩbor] 'jimboa'

d. [3i' mole] 'esmola'

(13) a. ['lifi] 'nariz

b. ['Jimi] 'ciúmes'

c. ['ifike] 'isca'

d. ['tofi] 'tosse'

Diferentemente do que foi descrito por Maurer no tocante à fricativa [3], o estudo não caracteriza a sua realização como rara, pelo contrário, é possível verificar um registro frequente, no entanto, não se pode negar que tal frequência está sujeita ao condicionamento de contextos definidos. Os exemplos reunidos em (12) e (13) compartilham o fato de apresentarem as consoantes [S] e [3] em uma mesma circunstância de realização: antecedendo a vogal/i/. Nesse sentido, Maurer (1995) defende que [S] e [3] são resultados do condicionamento da vogal /i/ e da aproximante /j/, não fazendo, portanto parte do sistema. A presente análise chegou à mesma conclusão quanto às fricativas pós-alveolares, posto que as mesmas se realizam sobretudo diante da vogal /i/, logo não se trata de fonemas, mas de alofones - quando estão diante de $/ \mathrm{i} / \mathrm{e} / \mathrm{j} / \mathrm{-}$ das fricativas interdentais surda $/ \theta /$ e sonora $/ \delta /$, respectivamente.

Na próxima seção, discutiremos a respeito do estatuto fonêmico ou alofônico do [r].

\section{$O$ angolar e o estatuto do [r]}

De acordo com Maurer (1995) e Lorenzino (1998), o rótico [r] apresenta um caráter fonêmico. Segundo Lorenzino (1998), o angolar teria duas líquidas (/1/ e /r/), sendo possível encontrar variação entre [1] e [r], sobretudo em posição intervocálica, 
como em fala $\sim$ fara $\sim$ fa 'falar'. O autor também aponta que o /d/ pode ser realizado como [r] nos contextos em que a consoante é antecedida de uma consoante nasal. Maurer (1995) defende que [d] seria uma variante de /r/, como em da $\sim$ ra 'dar'. A realização de /r/, um fonema do angolar para o autor, seria mais usual com o [r] do que com o [d], [d] apareceria mais no início da palavra, contudo o [r] não poderia ser excluído da posição, uma vez que ocorre em dia ria 'dia', por exemplo. Maurer (1995) salienta não ser evidente se [r] e [d] são intercambiáveis em todos os casos, mas admite não ter encontrado pares mínimos opondo [r] e [d]. De maneira análoga, para o presente estudo, também foi encontrada em nossos registros uma variação entre [r] e [d] em um número significativo de itens como em dêlu $\sim$ rêlu 'dinheiro'. Ademais, tal variação se estende, em um conjunto de itens, também à consoante lateral [1] como rêlu $\sim$ dêlu lêlu 'dinheiro' e dêvê lêvê rêvê 'dever', o que também foi apontado por Maurer (1995).

A divergência entre as propostas se dá pelo fato de Maurer (1995) apresentar /r/ como fonema (que se realiza ora como [r] ora como [d]) que se opõe ao fonema $/ 1 /$ como em rema dema 'pesar' e lema 'remar'. De fato, em nossos registros, observou-se uma variação lexical entre [r] e [d] e, em um número menor de itens, com [1] também, contudo não houve um dado sequer que apontasse o rótico como fonema na língua. Encontramos pares mínimos que demonstraram as consoantes /d/ e /1/ como fonemas distintos (data 'quantidade' versus lata 'lata'), entretanto não houve uma realização de [r] que justificasse um estatuto fonêmico, tendo em vista que o rótico está sempre em variação com [d] e, em alguns itens, com [d] e [1]. Em pesquisa de campo, notouse que há itens em que não é possível intercambiar [d] e [r] sob a pena de o falante identificar tal item como não pertencente ao angolar como dooba 'dobra' (*rooba) e disinu 'destino' (*risinu). Ao mesmo tempo, essa mesma natureza de explicação foi utilizada por falantes mais velhos para justificar a preferência do [r] em itens em que há variação com [d] (como kethara kethada 'mandíbula'): o dado item com a realização da consoante dento-alveolar sonora pertenceria supostamente ao português de acordo com esses informantes. Como se pôde observar, as avaliações subjetivas dos falantes não constituem um consenso. Contudo, tal contradição não é uma situação incomum no trabalho de campo. Labov (2008 [1972], p. 359), por exemplo, discutia décadas atrás sobre o abismo entre o que os falantes acreditam que dizem e o que de fato falam. Nesse sentido, o autor afirma: “[...] existem conjuntos de valores contrários que sustentam as formas vernáculas e que não aparecem nos testes de reação subjetiva." Dito isso, torna-se imprescindível que se realize um estudo com diversos experimentos sobre a variação entre [r] e [d] para que afirmações de fato precisas possam ser dadas.

A respeito do que pode ser afirmado neste momento, há evidências que apontam as consoantes $/ \mathrm{l} / \mathrm{e} / \mathrm{d} /$ como fonemas da língua. $\mathrm{O}$ rótico $[\mathrm{r}]$, por seu turno, tem sido observado em variação fundamentalmente com a consoante dento-alveolar surda, e às vezes, com /1/. Como já dito, há indícios que convergem para a existência fonêmica de /d/, o mesmo não pode ser afirmado sobre o [r], posto que, em contextos de variação entre [d] e [r], não houve realização categórica do rótico ou par mínimo que suporte seu 
estatuto distintivo. Em outras palavras, dada a ausência de pares mínimos em que só seja possível a realização de [r], a presente pesquisa opta por não propor sua inserção no quadro fonêmico da língua. É inegável que as duas consoantes se encontram em variação, no entanto a falta de maiores análises e ausência de oposição distintiva do [r] não possibilitam estabelecê-lo, com segurança, como fonema. A alternância fonética entre as líquidas [1] e [r] e [d] após consoante nasal é um fenômeno comum na maioria das línguas bantu (HYMAN; INKELAS, 2012). Nestas línguas, as líquidas podem ser resultado de modificações diacrônicas de fonemas oclusivos do proto-bantu (cf. HYMAN, 2001). No caso do angolar, língua que recebeu um maior aporte bantu, esta distribuição parece ter convergido para uma variação cujos fatores condicionantes ainda precisam ser identificados e analisados a partir de uma amostra maior. É salutar destacar que nada impede que, no futuro, na existência de dados que apontem para o caráter distintivo de [r], tal posicionamento seja revisto.

Após a discussão de aspectos relacionados ao quadro consonantal do angolar, apontando semelhanças e divergências quanto à análise de Maurer (1995) e de Lorenzino (1998), a seção seguinte se debruça sobre o quadro vocálico da língua.

\section{Quadro vocálico}

Quanto ao seu sistema vocálico, o angolar possui sete vogais orais simples e sete longas como se pode observar nos Quadros 12 e 13:

Quadro 12 - Vogais orais simples do angolar

\begin{tabular}{lccc}
\hline & Coronal & Central & Dorsal \\
\hline Alta & $\mathrm{i}$ & & $\mathrm{u}$ \\
Média-alta & $\mathrm{e}$ & & $\mathrm{o}$ \\
Média-baixa & $\varepsilon$ & $\mathrm{a}$ & 0 \\
Baixa & & $\mathrm{a}$ & \\
\hline
\end{tabular}

Fonte: Bandeira (2017, p.226).

Quadro 13 - Vogais orais longas do angolar.

\begin{tabular}{lccc}
\hline & Coronal & Central & Dorsal \\
\hline Alta & ii & & uu \\
Média-alta & ee & & oo \\
Média-baixa & $\varepsilon \varepsilon$ & & o \\
Baixa & & aa & \\
\hline
\end{tabular}

Fonte: Bandeira (2017, p.226). 
No que diz respeito à sua distribuição, as sete vogais orais /i e $\varepsilon$ a $\supset$ o u/possuem estatuto fonêmico que pode ser observado nos exemplos de (14) a (18). Tais vogais podem ocorrer em sílabas tônicas e átonas. Todas podem ser nasalizadas foneticamente diante de / $\mathrm{N} /$ e também em sílaba precedida por uma consoante nasal na sílaba seguinte, realizando-se como [ĩ ẽ $\tilde{\varepsilon} \tilde{\mathfrak{e}}$ ว̃ õ ũ].

(14) $/ \mathrm{a} / \mathrm{e} / \varepsilon /$

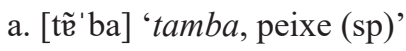
b. [tễ'bc] 'também'

(15) $/ \mathrm{e} / \mathrm{e} / \varepsilon /$
a. ['me] 'metade'
b. ['me] 'mesmo'

(16) $/ \mathrm{o} / \mathrm{e} / \mathrm{\rho} /$
a. [lo'lo] 'dor'
b. [lo'lo] 'lamber'

(17) $/ \mathrm{i} / \mathrm{e} / \mathrm{e} /$
a. ['vi] 'vinho'
b. ['ve] 'vez'

(18) $/ \mathrm{u} / \mathrm{e} / \mathrm{o} /$
a. ['bu] 'vir'
b. ['bo] $2 \mathrm{SG}^{13}$

No que concerne à mudança nas realizações das vogais condicionadas pelo acento, as vogais médias /e $\varepsilon>\mathrm{o} /$ se realizam da mesma maneira independentemente se estão em sílaba átona final, como se observa em (19).

(19) a. longô ['lõgo] 'longo'

b. kobo ['ksbo] 'buraco'

c. inhe ['inc] 'unha'

d. ikwê ['ikwe] 'grão'

Por outro lado, a vogal /i/ pode se realizar como [I] em sílabas átonas finais, em (20a). Quando ocorre em hiato, pode ser realizada como [j] após um processo de

\footnotetext{
13 Pronome de segunda pessoa do singular.
} 
ditongação, em (20b). A vogal alta dorsal arredondada realiza-se como [u] em sílabas tônicas, pré-tônicas e pós-tônicas não finais e como [ひ] em sílabas átonas finais, em (20c). Quando aparece em hiato, pode ser realizado como [w] após um processo de ditongação, em (20d). A vogal baixa /a/ realiza-se como [e] em sílabas átonas finais, em (20e).

(20) a. maxi ['mafi] 'mais'

b. mionga [mi' õge] $\sim$ ['mjõge] 'mar'

c. lalu ['lalv] 'doença de pele'

d. kueca $[\mathrm{ku}$ ' $k \mathrm{kr}] \sim$ ['kwekr] 'cueca'

e. lama ['lame] 'lama'

Para Maurer (1995), o sistema vocálico do angolar apresenta vogais nasais fonêmicas. Entretanto, durante a pesquisa de campo, não foi registrada, na fala dos informantes, oposição entre uma vogal nasal e uma vogal nasalizada por uma consoante nasal como, por exemplo, entre / $/ \tilde{\mathrm{e}} / \mathrm{e} / \mathrm{aN} /$. Defende-se, neste estudo, que, no angolar, a nasalidade é resultado de um processo de espalhamento de nasalidade, oriunda de uma consoante nasal /N/ em coda, com nasalização vocálica obrigatória, como em (21), ou de uma consoante nasal da sílaba seguinte, opcional, por isso sujeita à variação, em (22). Sendo assim, não há nasalidade fonêmica das vogais, haja vista que a nasalidade é decorrente de um processo, assim como ocorre em lung'Ie (AGOSTINHO, 2015) e santome (BALDUINO et al., 2015). Há evidências para essa análise também nos jogos de linguagem supracitados, em que a nasal se comporta como coda (cf. ARAUJO; AGOSTINHO, 2014; AGOSTINHO, 2015, 2016), como pode ser observado no exemplo (06c).

Há dois processos de nasalização regressiva: por coda nasal na mesma sílaba ou por onset nasal na sílaba seguinte, conforme também atestado para o lung'Ie (AGOSTINHO, 2015). O processo de nasalização por coda nasal /N/ nasaliza a vogal à esquerda, como podemos observar a seguir:

(21) Nasalização provocada por coda nasal - Obrigatório

a. ['mẽge] /maNga/ 'manga'

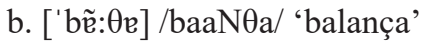

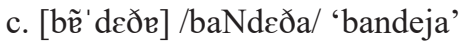

Este processo é obrigatório e ocorre em sílabas tônicas e átonas. O processo de nasalização por consoante nasal da sílaba seguinte é opcional, como podemos observar a seguir: 
(22) Nasalização provocada por consoante no onset da sílaba seguinte-Opcional

a. [lũ' migo] [lu' migo] 'inimigo'

b. [mẽ' nelv] [ma'nelv] 'marinheiro'

c. [mĩ'nisv] [mi'nisv] 'ministro'

Como em lung'Ie (AGOSTINHO, 2015), em angolar, as vogais longas são fonologicamente distintas das simples, como nos exemplos de (23) a (28):

(23) a. $/ \mathrm{a} /\left[\right.$ 'ta] $\mathrm{TMA}^{14}$

b. /aa/ ['ta:] 'cortar'

(24) a. /e/ ['e] $3 \mathrm{SG}^{15}$

b. /ee/ ['e:] 'sim'

(25) a. $/ \varepsilon /[$ 'm $\varepsilon]$ 'mesmo'

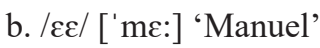

(26) a. /// [go' pa] 'gopa, tipo de bebida'

b. /os/ [go:' pa] 'garoupa'

(27) a. /o/ [' $\theta$ oko] 'soco'

b. /oo/ [' $\theta$ o:ko] 'charoco'

(28) a. /u/ ['kuӨv] 'peso de areia'

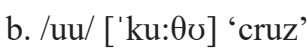

Como as vogais simples, as vogais longas também são passíveis de nasalização como em (29):

(29) a. /aaN/ ['lẽ:ðe] 'laranja'

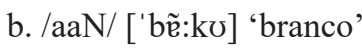

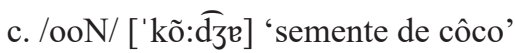

Em nossa análise, utilizaremos a notação /aa/ para a forma subjacente e a notação [a:] para a forma de superfície, já que foneticamente esses dois segmentos são realizados como uma vogal longa. Assumimos aqui a mesma estrutura proposta por

14 Partícula de tempo, modo e aspecto.

15 Pronome de terceira pessoa do singular. 
Agostinho (2015) para o lung'Ie, que considera que se trata de uma vogal com duas moras, e que uma sequência de dois tons é atribuída à sílaba com vogal longa e cada mora recebe um tom. A sílaba pode ser representada da seguinte maneira:

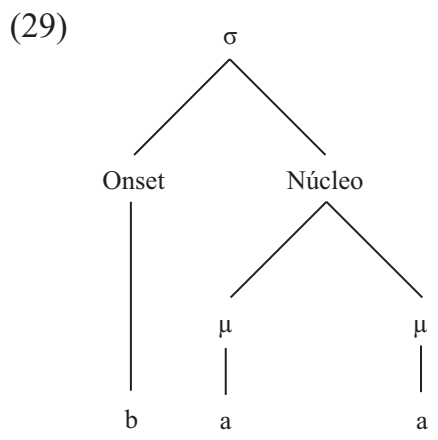

Fonte: Agostinho (2015, p.77).

Após a discussão de aspectos do quadro vocálico, como a existência de vogais nasais e a representação das vogais longas, a seção seguinte trata da estrutura silábica do angolar.

\section{A sílaba}

A partir dos nossos dados, constatamos que no onset pode haver uma ou duas consoantes, assim o onset pode ser C, CG e CC, em que a consoante na segunda posição do onset pode ser /j/, /w/, /1/ e [r]. Assumimos aqui a mesma posição de Agostinho (2015; 2016) para o lung'Ie e de Araujo e Agostinho (2014) para o fa d'Ambô em relação aos glides, uma vez que as três línguas são geneticamente relacionadas. Para os autores, os glides se comportam como consoantes no jogo de linguagem. Ademais, Agostinho (2015, 2016) apresenta argumentos fonotáticos para esta análise.

De acordo com a análise dos dados coletados e com as descrições de Maurer (1995) e Lorenzino (1998), o angolar apresentaria os seguintes padrões silábicos: V, VV, CV, CVV, CGV, VC ${ }^{16}$. No Quadro 14, são apresentados os moldes silábicos possíveis em angolar, a partir da análise do corpus deste estudo: $\mathrm{V}, \mathrm{N}, \mathrm{VN}, \mathrm{CV}, \mathrm{GV}$, CVN, CGV, CGVN, VV, CCV, CVV e CVVN. No que tange à sua estrutura silábica, a única consoante que pode ocupar a posição de coda é a nasal /N/, como em /baNbu/ ['bẽbu] 'bambu'. Foram encontrados apenas dois registros de itens que apresentavam a aproximante palatal /j/ na posição de coda (['paj] em 'pai nosso (oração)' e ['bajle] 'baile'), diante disso, é preciso que sejam analisados mais dados com a consoante na referida posição para que seja possível definir se ainda há restrições silábicas quanto à

16 Onde há V, leia-se vogal; C, consoante; N, nasal; G, glide/aproximante. 
consoante aproximante /j/ em coda. Assim, esse molde silábico não será representado abaixo. Ademais, não houve itens que apresentassem a consoante aproximante /w/ na referida posição. O núcleo deve ser preenchido por pelo menos uma vogal simples ou por uma nasal silábica, sendo a sílaba mínima $\mathrm{V}$ ou N. Como nas demais línguas-irmãs, em angolar, a nasal silábica é uma consoante hospedeira, ocorrendo em conjunto com outra consoante como em [y. 'ge] /Nge/ 'ser humano'. Ademais, das línguas-filhas do PGG, o angolar é a mais refratária ao preenchimento da coda, permitindo apenas que a consoante $/ \mathrm{N} /$ a ocupe.

Quadro 14 - Moldes silábicos do angolar

\begin{tabular}{|c|c|c|c|}
\hline Sílaba & Exemplos & Forma Subjacente & Glosa \\
\hline $\mathbf{V}$ & ['o] & $/ \mathrm{o} /$ & $2 \mathrm{PL}^{17}$ \\
\hline $\mathbf{N}$ & [y.' 'ge] & /Nge/ & 'ser humano' \\
\hline $\mathbf{V N}$ & 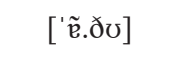 & /aNðu/ & 'recém-nascido' \\
\hline $\mathrm{CV}$ & ['bi. $\theta v]$ & $/ \mathrm{bi} \theta \mathrm{u} /$ & 'bicho' \\
\hline GV & ['pa.je] & /paja/ & 'praia' \\
\hline CVN & [lex.'ba] & /laNba/ & 'cubrir' \\
\hline CGV & {$[\theta a . ' g w a]$} & /Oagwa/ & 'enxaguar' \\
\hline CGVN & ['kwẽ.de] & /kwaNda/ & 'cume' \\
\hline VV & ['e:] & /ee/ & 'sim' \\
\hline CVV & ['fa:.kv] & /faaku/ & 'fraco' \\
\hline CVVN & ['lẽ:.ðе] & /laaNða/ & 'laranja' \\
\hline \multirow[t]{2}{*}{$\mathrm{CCV}^{18}$} & [bi.fi.'kle.te] & /biOikleta/ & 'bicicleta' \\
\hline & {$[\operatorname{tr\varepsilon } . \operatorname{tr} \varepsilon]$} & /tretre/ & 'espécie de pássaro' \\
\hline
\end{tabular}

Fonte: Adaptado de Bandeira (2017, p.230).

A seguir apresentamos o esquema da sílaba fonológica em angolar, a partir da proposta binária com rima:

17 Pronome de segunda pessoa do plural.

18 Ver próxima seção a respeito do [r]. 
Esquema 1 - Esquema da sílaba em angolar

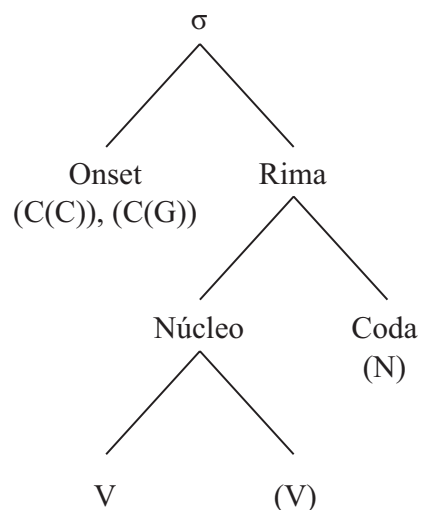

Fonte: Elaboração própria.

Quando há uma nasal silábica, não é possível haver outros elementos na sílaba, e a estrutura é a seguinte:

Esquema 2 - Esquema da nasal silábica em angolar

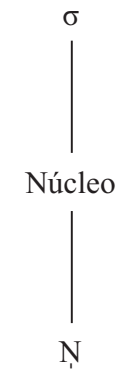

Fonte: Elaboração própria.

\section{$O$ angolar e onsets complexos}

Em pesquisa de campo, encontramos itens como bixikleta [bifi 'klete] 'bicicleta' e kontra ['kõtre] 'amuleto'. Em vez de xtaka [' Jtake] 'estaca' como sugerido por Maurer (1995), foi coletado o item xitaka [ $\int_{1}$ 'take] 'estaca'. Adicionalmente, registrou-se um item que apresentava /p/ na primeira posição de um onset complexo com a consoante lateral /1/ na segunda posição (templa ['tẽple] 'tempero'). No entanto, o mesmo item se encontra em variação com a realização sem a consoante /1/ na segunda posição do onset, mas com a aproximante /j/ em seu lugar (tempya ['tẽpje] 'tempero'). Soma-se a essas questões o fato de que, em santome, há o mesmo item lexical templa ['tẽple] 
'tempero', diante disso, pode-se conjecturar que o item pode ter entrado via empréstimo. Assim como ocorreu com o /p/, foram encontrados registros de itens que apresentavam /b/ na primeira posição de um onset complexo com a consoante lateral /1/ na segunda posição, como, por exemplo, [bla'boze] 'babosa, aloe vera', tendo em vista que, em santome, há um item idêntico como blaboza [bla'boze] 'babosa, aloe vera', é possível considerar os referidos itens como uma influência via contato. Contudo, é salutar tecer algumas considerações sobre assumir os registros de onsets complexos como resultados de empréstimo. Primeiramente, é preciso definir o conceito de empréstimo utilizado nesse estudo: toda palavra simples ou composta, ou uma sentença oriunda de segunda língua (L2), incorporada ao discurso da primeira língua (L1). Nesse sentido, a nativização ou a adaptação dos empréstimos de L2 em L1 são regidas por padrões fonológicos de L1, padrões impostos pelos falantes de L1 (cf. PARADIS; LABEL, 1994). No tocante à adaptação de empréstimos, Paradis (1996) afirma que os falantes de L1 tendem a interpretar a estrutura de L2 conforme a estrutura de L1. Por essa razão, os falantes de L1 frequentemente descartam, das palavras incorporadas via empréstimo, informações, contidas em L2, percebidas como redundantes ou proibidas do ponto de vista de L1. No percurso de L2 (nesse caso, santome e português) até L1 (o angolar) ocorreu e ainda ocorre uma série de modificações, uma vez que são línguas diferentes. Em contrapartida, ao observar itens do léxico básico da língua (ver Quadro 15), constata-se que o angolar não manteve onsets complexos in situ provenientes de sua língua-mãe, o protocrioulo (BANDEIRA, 2017), apresentando estratégias de adaptação como o apagamento da consoante líquida *1 na segunda posição do onset, que podia ser seguido ou não pelo alongamento compensatório.

Quadro 15 - Dissolução dos onsets complexos provenientes do protocrioulo em angolar

\begin{tabular}{|c|c|c|}
\hline Protocrioulo & Angolar & Glosa \\
\hline *'blasu & ['ba: $\theta v]$ & 'braço' \\
\hline *'blaNku & 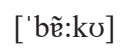 & 'branco' \\
\hline *'gleza & ['ge:ðe] & ‘igreja’ \\
\hline *'pletu & ['pe:to] & 'preto' \\
\hline *'plaga & ['pa:ge] & 'praga' \\
\hline *so'pla & [so'pa] & 'assoprar' \\
\hline
\end{tabular}

Fonte: Dados retirados de Bandeira (2017).

Contudo, mesmo que o vocabulário básico do angolar evidencie a ausência estrutural de onsets complexos, itens como tre.tre [trع'trع] 'espécie de pássaro', bi.xi.kle.ta [bifi'klete] 'bicicleta' e kon.tra ['kõtre] 'amuleto' - ao serem empregados pelos falantes - podem indicar uma possível mudança no quadro da língua. No entanto, é necessária a observação de um número maior de dados que apresentem 
tal configuração silábica para maiores afirmações nesse sentido. Entretanto, cumpre destacar que, se os falantes utilizam as palavras com o referido molde silábico, tais estruturas provavelmente são permitidas e possíveis, de outro modo itens como bixikleta [bifi'klete], por exemplo, passariam por uma adaptação, tal como ocorreu no passado da língua (*'blasu > baathu ['ba: $\theta v]$ 'braço'). Isso pode ser observado mesmo no presente através do item xitaka [ $\int \mathrm{i}$ 'take] em vez de xtaka ['Jtake] 'estaca' (santome), tendo em vista que o angolar não aceita onsets formados com a fricativa [ $]$ ] e consoantes oclusivas como [t] - estrutura possível em santome -, a língua apresenta o item com sílabas $\mathrm{CV}$, sem o onset complexo [ $\mathrm{f}]$, resultando em xitaka [ $\int 1$ ' take] 'estaca'.

É importante salientar que a variação entre [d] e [r] na posição de onset simples deve ser observada de forma distinta se comparada à realização de [r] na segunda posição do onset complexo em razão de dois aspectos: avaliação e distribuição. No tocante aos itens com a realização de [r] em variação com [d] na posição do onset simples, muitos falantes mono e bilíngues os avaliavam positivamente, alegando que tais itens são de natureza "mais crioula" ou "não portuguesa". Além disso, tal variação é observada em inúmeros itens. $\mathrm{O}$ mesmo não pode ser dito quanto à presença do [r] na segunda posição do onset. No tocante à avaliação, itens com onsets complexos em geral não foram bem recebidos pelos falantes em pesquisa de campo. Os mesmos reiteradamente identificavam tais constituições como itens do português, não do angolar. Além disso,

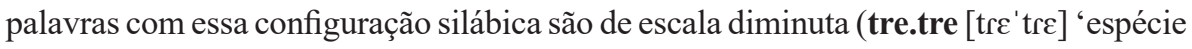
de pássaro', kon.tra ['kõtre] 'amuleto').

Assim, diante de poucos itens com /r/ ocupando a segunda posição, é possível apenas hipotetizar que tal rótico esteja sendo fonologizado no angolar. No momento sua presença é marginal se comparado às demais consoantes, posto que se realiza de maneira irregular em um pequeno número de itens, não havendo ainda pares mínimos que possam corroborar seu estatuto fonológico de forma categórica. Por essa razão, o estudo defende a notação da consoante $[r]$ entre colchetes no quadro consonantal do angolar, podendo ser modificado no momento em que houver evidências que levem à anuência do seu estatuto fonêmico.

Essa seção apresentou algumas questões relacionadas a uma possível formação de onset complexo no angolar, sendo a seção seguinte reservada às considerações finais do estudo.

\section{Considerações finais}

O presente estudo teve como objetivo precípuo apresentar uma descrição de aspectos fonológicos recentes da língua para que, simultaneamente, fosse possível comparar as atuais descobertas com aquelas encontradas por Maurer (1995) e Lorenzino (1998), as primeiras descrições sobre o angolar. Em vista disso, foram levantados aspectos que indicavam convergências e dissonâncias com as referidas descrições. 
Como quadro fonêmico, a presente análise defende que o angolar possui dezesseis consoantes (/p, b, t, d, k, g, f, v, $\theta$, ə l, m, n, n, j, w), sete vogais orais simples (/i, e, $\varepsilon$, $\mathrm{a}, \mathrm{\jmath}, \mathrm{o}, \mathrm{u} /$ ) e sete longas (/ii, ee, $\varepsilon \varepsilon$, aa, ๖, ,o, uu/). No que diz respeito aos aspectos dissonantes em relação às propostas de Maurer (1995) e Lorenzino (1998), o estudo aponta que os segmentos [ $\widehat{\mathrm{t} f}]$ e [ $\widehat{\mathrm{d}} 3]$ não são fonemas, mas alofones das consoantes /t/ e /d/ quando em adjacência à vogal /i/ ou ao aproximante /j/. Ademais, para essa pesquisa, como defendido por Lorenzino (1998), a consoante / $\mathrm{n} /$ apresenta um estatuto fonêmico, posto que cumpre função distintiva na língua, o que não ocorre com o rótico [r] cujo estatuto fonêmico é incerto, dada a ausência de pares mínimos. Tal posição diverge do postulado por Maurer (1995) que inseriu o [r] no quadro de consoantes fonêmicas do angolar.

Defendemos adicionalmente não haver vogais nasais em angolar, em vez disso constatamos que consoantes nasais condicionam a nasalização vocálica. Tal processo de nasalização não apresenta estatuto fonológico, apenas fonético e restrito a contextos condicionantes - quando há uma consoante nasal em coda silábica, sendo a nasalização vocálica obrigatória, ou quando há uma consoante nasal no onset da sílaba seguinte, nesse caso, a nasalização é opcional. No que se refere às consoantes nasais $/ \mathrm{m}, \mathrm{n} / \mathrm{em}$ início de palavra diante de outra consoante, assumimos uma consoante nasal /N/, uma vez que, nesse contexto, a consoante nasal não possui ponto de articulação definido, assimilando o ponto da consoante seguinte. Com a finalidade de estabelecer os moldes silábicos, Maurer (1995) e Lorenzino (1998) registraram as seguintes combinações: V, VV, CV, CVV, CGV, VC. Por outro lado, a partir da análise do corpus, observamos que as possibilidades silábicas em angolar são mais diversas daquelas registradas anteriormente, a saber: V, N, VN, GV, CV, CVN, CGV, CGVN, VV, CCV, CVV e CVVN.

No que refere aos aspectos convergentes entre as análises, o estudo se coaduna com a afirmação de Maurer (1995) e Lorenzino (1998) a respeito do estatuto fonológico das consoantes fricativas interdentais, tendo em vista que $/ \theta /$ e $/ ð /$ cumprem função distintiva na língua, indicando oposições fonológicas e, por conseguinte, semânticas. Em vista disso, defendemos que a interdental surda $/ \theta /$ é um fonema, realizando-se foneticamente como [s] ou até mesmo como [J] diante de /i/ ou /j/, ao mesmo tempo a interdental sonora /ð/ é, de igual modo, fonema, realizando-se foneticamente como [z] ou como [3] diante de $/ \mathrm{i} / \mathrm{ou} / \mathrm{j} /$.

No que tange à necessidade e à importância desse estudo, embora o angolar apresente, ainda hoje, um universo de 11.377 falantes como primeira ou segunda línguas (INE, 2013), não havia estudos que descrevessem a sua fonologia de forma sistemática de tal modo que uma das análises mais extensas foi publicada há mais de vinte anos (MAURER, 1995), seguida três anos depois pela discussão de Lorenzino (1998). Devido a lacunas nas descrições do angolar, foi imprescindível investigar seu sistema fonológico de tal modo que esta descrição, devido ao seu escopo, constitui também uma contribuição ao estudo da fonologia da língua, posto que é uma proposta de análise original de seus aspectos fonológicos, oferecendo novas descrições de aspectos linguísticos para os estudos das línguas de contato, em geral, e do angolar, em particular. 


\section{Agradecimentos}

Manuele Bandeira agradece à FAPESP (Processo 2013/08100-4), ao CNPq (Conselho Nacional de Desenvolvimento Científico e Tecnológico) (Processo 150051/2018-2) ao Programa de Filologia e Língua Portuguesa (USP) (Projeto 2018-278) pelo apoio financeiro. Ana Lívia Agostinho agradece ao CNPq (Processo 200519/2019-0) pelo suporte financeiro para esta pesquisa.

BANDEIRA, M.; AGOSTINHO, A. L.; FREITAS, S. Phonetic-phonological aspects of the modern Angolar. Alfa, São Paulo, v.65, 2021.

- ABSTRACT: This work addresses Angolar, a native language of São Tomé and Príncipe. It aims to (i) investigate its phonetic-phonological aspects, and (ii) compare the research results with Maurer (1995) and Lorenzino (1998), two of the first descriptions. The corpus is constituted by 3,000 items collected in two field trips (in 2014 and 2018) to the community of São João dos Angolares in São Tomé. Regarding the consonants, we argue that Angolar has sixteen phonemes: / $p, b, t, d, k, g, f, v, \theta, \delta, l, m, n, n, j, w /$ This study differs from the analyses of Maurer (1995) and Lorenzino (1998) because it considers [t]], [ $\left.\widehat{d_{3}}\right]$ and [r] as allophones. On the other hand, all three studies agree as for the phonological status of interdental fricatives. Regarding the vowel inventory, Angolar has fourteen oral vowels: $i, e, \varepsilon, a, \supset, o, u$, ii, ee, $\varepsilon \varepsilon$, aа, эs, oо, uи/. Nasal realizations are possible. Finally, regarding syllable structure, there is a larger number of syllable templates, including a possibility of realization of complex onsets. With this study, it is possible to know more about Angolar phonology, to shed new light on a still little studied language, and to contribute to the area of Contact Linguistics.

- KEYWORDS: modern Angolar; vowel inventory, consonant inventory; syllabic structure.

\section{REFERÊNCIAS}

AGOSTINHO, A. L. Fonologia do lung'Ie. München: Lincom, 2016. (Lincom Studies in Pidgin and Creole Linguistics, 15).

AGOSTINHO, A. L. Fonologia e método pedagógico do lung'Ie. 2015. 446f. Tese (Doutorado em Filologia e Língua Portuguesa) - Faculdade de Filosofia, Letras e Ciências Humanas, Universidade de São Paulo, São Paulo, 2015.

AGOSTINHO, A. L.; ARAUJO, G. A. Playing with language: three language games in the Gulf of Guinea. Language Documentation \& Conservation, Honolulu, v.15, p.219-238, 2021.

AGOSTINHO, A. L.; HYMAN, L. M. Word-prosody in Lung'Ie: one system or two? Probus, Berlin, v.33, n.1, p.57-93, 2021. 
AGOSTINHO, A. L.; SOARES, E. C.; MENDES, M. C. Merging of quasi-phonemes in contact situations: evidence from rhotics in Principense Portuguese. 2020. Poster apresentado no evento Annual Meeting on Phonology.

ARAujO, G. A. de; AGOSTINHO, A. L. Padronização das línguas nacionais de São Tomé e Príncipe. Língua e Instrumentos Linguísticos, Campinas, v.26, p.49-81, 2010.

ARAUJO, G. A. de; AGOSTINHO, A. L. Fa do Vesu: a language game of Fa d'Ambô. PAPIA, São Paulo, v.24, n.2, p.265-281, jul./dez. 2014.

ARAUJO, G. A. de; BANDEIRA, M. Dicionário Angolar-Português. Em preparação.

ANDRADE, E. Línguas africanas: breve introdução à fonologia e morfologia. Lisboa: A. Santos, 2007.

BAKER, G. Palatal phenomena in Spanish phonology. 2004. 290f. Tese (Doutorado em Filosofia) - Universidade da Flórida, Flórida, 2004.

BALDUINO, A. M. et al. A nasalidade vocálica em santome e lung’Ie. Papia, São Paulo, v.25, n.1, p.7-25, 2015.

BANDEIRA, M. Reconstrução fonológica e lexical do protocrioulo do Golfo da Guiné. 2016. 440f. Tese (Doutorado em Filologia e Língua Portuguesa) - Faculdade de Filosofia, Letras e Ciências Humanas, Universidade de São Paulo, São Paulo, 2017.

BOTNE, R; DAVIS, S. Language games, segment imposition, and the syllable. Studies in Language, v.24, n.2, p.319-344, 2000.

CHATELAIN, H. Grammatica elementar de Kimbundu ou língua de Angola. Genebra: Typographia de Charles Schuchardt, 1888-1889.

CEITA, M. N. Ensaio para uma reconstrução histórico-antropológica dos angolares de S. Tomé. Trabalho de Conclusão de Curso (Pós-Graduação em Desenvolvimento Social e Económico em África) - Centro de Estudos Africanos, Instituto Universitário de Lisboa, 1991.

DAVIS, S.; HAMMOND, M. 1995. On the Status of Onglides in American English. Phonology, Cambridge, v.12, n.2, p.159-182, 1995.

FERRAZ, L. I. A Linguistic appraisal of Angolar. Memoriam Antônio Jorge Dias, Lisboa, v.2, p.177-186, 1974.

FERRAZ, L. I. The creole of São Tomé. Johannesburg: Witwatersrand University Press, 1979.

GÜNTHER, W. Das Portugiesische Kreolisch der ilha do Príncipe. Marburgo: Marburg an der Lahn, 1973. 
HAGEMEIJER, T. Initial vowel agglutination in the Gulf of Guinea creoles. In: ABOH, E.; SMITH, N. (ed.). Complex processes in new languages. Amsterdam: Filadélfia: John Benjamins Publishing Company, 2009. p.29-50.

HYMAN, L. M. The limits of phonetic determinism in phonology: *NÇ revisited. In: HUME, B.; JOHNSON, K. (ed.). The role of speech perception Phenomena in Phonology. San Diego: Academic Press, 2001. P.141-185.

HYMAN, L. M.; INKELAS, S. Complementarity and Opacity: [1] [d] in Bantu. UC Berkeley PhonLab Annual Report, [s.l.], v.8, n.8, p.321-326, 2012.

INE. Recenseamento geral da população e da habitação: características educacional da população. São Tomé: INE, 2013.

LABOV, W. Padrões sociolinguísticos. Tradução de Marcos Bagno; Marta Scherre e Caroline Cardoso. São Paulo: Parábola, 2008.

LADHAMS, J. Article agglutination and the African contribution to the Portuguesebased creoles. In: BARTENS, A.; BAKER, P. Black through white: African words and calques which survived slavery in creoles and transplanted European Languages. London: Battlebridge Publications, 2007. p.29-47.

LOREnZINO, G. A. The Angolar creole Portuguese of São Tomé: its grammar and sociolinguistic history. 1998. 295f. Tese (Doutorado em Filosofia) - Faculdade de Graduação em Linguística, Universidade de Nova York, Nova York, 1998.

MAPMAKER Interactive. Disponível em: http://mapmaker.nationalgeographic.org/. Acesso em: 10 maio 2016.

MAURER, P. L’Angolar: un créole afroportugais parlé à São Tomé; Notes de grammaire, textes, vocabulaires. Hamburg: Helmut Buske Verlag, 1995.

MAURER, P. Principense: grammar, texts, and vocabulary of the Afro-Portuguese creole of the Island of Príncipe, Gulf of Guinea. London: Battlebridge Publications, 2009.

NGUNGA, A. Introdução à linguística bantu. Maputo: Imprensa universitária da Universidade Eduardo Modlane, 2004.

PARADIS, C. The inadequacy of filters and faithfulness in Loanword Adaptation. In: DURAND, J.; LAS, B. Current trends in phonology. Salford: University of Salford Publications, 1996. p.509-534.

PARADIS, C.; LABEL, C. Contrasts from segmental parameter settings in loanwords: core and periphery in Quebec French. In: CONFERENCE ON CONTRASTS IN PHONOLOGY, 13., 1994, Toronto. Proceedings of the MOT. Toronto: University of Toronto, 1994. p.75- 94. 
SEIBERT, G. Os angolares da Ilha de São Tomé: náufragos, autóctones ou quilombolas? Dossiê História Atlântica, Brasília, v.12, n.1/2, p.43-64, 2004.

TRAILL, A.; FERRAZ, L. I. The interpretation of tone in Principense creole. Studies in African Linguistics, Gainesville, v.22, n.2, p.205-15, 1981.

WEINREICH, U.; LABOV, W.; HERZOG, M. Fundamentos empíricos para uma teoria da mudança linguística. Tradução de Marcos Bagno; revisão técnica de Carlos Alberto Faraco. São Paulo: Parábola, 2006.

Recebido em 6 de dezembro de 2019

Aprovado em 22 de setembro de 2020 